\title{
Publisher Correction: QTL mapping and molecular characterization of the classical $D$ locus controlling seed and flower color in Linum usitatissimum (flax)
}

\author{
Gurudatt Pavagada Sudarshan ${ }^{1,5}$, Manoj Kulkarni ${ }^{1}$, Leonid Akhov ${ }^{1}$, Paula Ashe ${ }^{1}$, Hamid \\ Shaterian ${ }^{1}$, Sylvie Cloutier ${ }^{2}{ }^{2}$, Gordon Rowland ${ }^{3}$, Yangdou Wei ${ }^{4}$ \& Gopalan Selvaraj ${ }^{1}$
}

Correction to: Scientific Reports https://doi.org/10.1038/s41598-017-11565-7, published online 16 November 2017

Due to a technical error in the publication of the original version of this Article, Gurudatt Pavagada Sudarshan, Manoj Kulkarni, and Leonid Akhov-who were originally named as equally contributing authors-were not identified as such. This has now been corrected in the PDF and HTML versions of the paper.

(i) Open Access This article is licensed under a Creative Commons Attribution 4.0 International cc. License, which permits use, sharing, adaptation, distribution and reproduction in any medium or format, as long as you give appropriate credit to the original author(s) and the source, provide a link to the Creative Commons license, and indicate if changes were made. The images or other third party material in this article are included in the article's Creative Commons license, unless indicated otherwise in a credit line to the material. If material is not included in the article's Creative Commons license and your intended use is not permitted by statutory regulation or exceeds the permitted use, you will need to obtain permission directly from the copyright holder. To view a copy of this license, visit http://creativecommons.org/licenses/by/4.0/.

(C) The Author(s) 2018

\footnotetext{
${ }^{1}$ National Research Council of Canada, 110 Gymnasium Place, Saskatoon, SK S7N 0W9, Canada. ${ }^{2}$ Agriculture and Agri-Food Canada, 960 Carling Avenue, Ottawa, ON K1A 0C6, Canada. ${ }^{3}$ Crop Development Centre, Department of Plant Science, University of Saskatchewan, Agriculture Building, 51 Campus Drive, Saskatoon, SK S7N 5A8, Canada. ${ }^{4}$ Department of Biology, University of Saskatchewan, 112 Science Place, Saskatoon, SK S7N 5E2, Canada. ${ }^{5}$ Present address: Bayer CropScience, Crop Analytics Morrisville, TECHIII 407 Davis Drive, Morrisville, NC, 27560, USA. Gurudatt Pavagada Sudarshan, Manoj Kulkarni and Leonid Akhov contributed equally to this work. Correspondence and requests for materials should be addressed to G.S. (email: gopalan.selvaraj@nrc.ca)
} 